Proceedings of the 24th International Symposium "The Environment and the Industry" (E-SIMI 2021), 24 September 2021, online event

\title{
Screening of cultivation media for LDPE biodegradation by Penicillium verrucosum CNM-FP-02
}

\section{OLGA POSTOLACHI $^{1 *}$, INNA RASTIMESINA ${ }^{1}$, VALENTINA JOSAN $^{1}$, VERA MAMALIGA ${ }^{1}$, ALINA COTOMAN ${ }^{1}$, DUMITRU STATI ${ }^{2}$, TATIANA GUTUL ${ }^{2}$}

\author{
${ }^{1}$ Institute of Microbiology and Biotechnology, 1 Academiei Str., Chisinau, MD-2028, email: oleseap@yahoo.com. \\ Republic of Moldova \\ ${ }^{2}$ Institute of Electronic Engineering and Nanotechnologies 'D.Ghitu', 3/3 Academiei Str., Chisinau, MD-2028, \\ Republic of Moldova \\ *Corresponding author: oleseap@yahoo.com
}

$\begin{array}{lll}\text { Received: } & \text { Accepted: } & \text { Published: } \\ \text { 13.08.2021 } & 13.12 .2021 & 17.12 .2021\end{array}$

\begin{abstract}
The paper's aim was to select the optimal mineral medium for LDPE biodegradation by the strain Penicillium verrucosum CNM-FP-02. It was selected 5 mineral salt media (MSM), which differed in salt content and N/P ratio. After 40 days of submerged cultivation, the following parameters were determined: catalase activity and $\mathrm{pH}$ of cultural media, biomass accumulation, rate of LDPE degradation, optical microscopy and the tensile testing of polyethylene. It was observed that catalase activity on all media, except MSM 4, was higher in the presence of LDPE. The addition of polyethylene to the growth media stimulated the fungal biomass accumulation by 19.3-93.1\% (4 media out of 5 tested). The percentage of degradation of LDPE films was different, depending on the culture medium, from $0.41 \%$ to $0.92 \%$. The most active LDPE films were degraded on medium MSM 2. Visualization of plastic strips under an optical microscope revealed the immobilization of the microorganism and the damage on the polyethylene surface. The tensile test showed increased elasticity of the plastic in the variants treated with fungal strain. In conclusion, in order to stimulate the biodegradation of LDPE by the strain P. verrucosum CNM-FP-02, the medium MSM 2 (N/P ratio 1:1) was selected.
\end{abstract}

Keywords: catalase activity, LDPE biodegradation, mineral salt media, Penicillium verrucosum.

\section{INTRODUCTION}

Due to its versatile properties, such as waterproof, strong, stability and durability, plastic materials are widely used in the modern economy. Low-density polyethylene (LDPE), the most common plastic, has become a major source of environmental pollution because it is inert and extremely recalcitrant to natural biodegradation processes [1-3].

The polyethylene can be degraded in various methods: chemical degradation, thermal degradation, photo degradation and biological degradation [4-6]. When compared to other methods, biodegradation is the best method, because it is cheap and does not generate harmful pollutants [79]. The use of microorganisms in plastic biodegradation is based on their ability to produce extracellular enzymes, which cleaves polymers into low-molecular weight fragments. These fragments are used by microbes as a source of carbon and energy [1, 7, 9-14].

The initial stage of microbial degradation usually include isolation of microorganisms from different sources (soil, plastic debris, solid waste, dumps sites, or landfill areas, water and water 
waste) by use of conventional, culture-dependent methods to find best potential microbial ability to degrade polymeric polyethylene chain [10, 14-18]. For the screening of microorganisms capable of degrading LDPE different mineral salt media (MSM) have been reported in the scientific literature $[8,16,17,19-21]$

Thus, the aim of our research was to select the optimal mineral medium for LDPE biodegradation by the strain Penicillium verrucosum CNM-FP-02.

\section{MATERIALS AND METHODS}

The object of study was strain Penicillium verrucosum CNM-FP-02, stored in the National Collection of Non-Pathogenic Microorganisms.

LDPE sheets used in this work were produced by Kraus Folie Sp.J. Film thickness was $35 \mu \mathrm{m}$. LDPE films were cut into longitudinal and transverse strips, weighed and sterilized by washing with $70 \%$ alcohol for $15 \mathrm{~min}$, and treated with UV-rays for 1 hour twice.

It was selected 5 mineral salt media (MSM), which differed in salt content and N/P ratio (Table 1). The composition of the mineral media was as follows, $\mathrm{g} / \mathrm{L}$ :

- MSM 1: $\mathrm{K}_{2} \mathrm{HPO}_{4}-7.0, \mathrm{KH}_{2} \mathrm{PO}_{4}-2.0, \mathrm{NH}_{4} \mathrm{NO}_{3}-1.0, \mathrm{MgSO}_{4} \cdot 7 \mathrm{H}_{2} \mathrm{O}-0.1, \mathrm{FeSO}_{4} \cdot 7 \mathrm{H}_{2} \mathrm{O}$ $-0.01, \mathrm{MnSO}_{4} \cdot 6 \mathrm{H}_{2} \mathrm{O}-0.002, \mathrm{ZnSO}_{4} \cdot 7 \mathrm{H}_{2} \mathrm{O}-0.001, \mathrm{CuSO}_{4} \cdot 7 \mathrm{H}_{2} \mathrm{O}-0.0001$ [8];

- MSM 2: $\mathrm{K}_{2} \mathrm{HPO}_{4}-1.0, \mathrm{KH}_{2} \mathrm{PO}_{4}-1.0, \mathrm{NH}_{4} \mathrm{NO}_{3}-1.0,\left(\mathrm{NH}_{4}\right)_{2} \mathrm{HPO}_{4}-1.0, \mathrm{MgSO}_{4} \cdot 7 \mathrm{H}_{2} \mathrm{O}-$ $0.2, \mathrm{FeCl}_{3}-0.05, \mathrm{CaCl}_{2}-0.02[19]$;

- MSM 3: $\mathrm{K}_{2} \mathrm{HPO}_{4}-7.0, \mathrm{KH}_{2} \mathrm{PO}_{4}-2.0,\left(\mathrm{NH}_{4}\right)_{2} \mathrm{HPO}_{4}-1.0, \mathrm{MgSO}_{4} \cdot 7 \mathrm{H}_{2} \mathrm{O}-0.1$, $\mathrm{Na}_{3} \mathrm{C}_{6} \mathrm{H}_{5} \mathrm{O}_{7}-0.5$ [16];

- MSM 4: $\mathrm{FeCl}_{3}-10.0, \mathrm{NaNO}_{3}-2.0, \mathrm{MgSO}_{4} \cdot 7 \mathrm{H}_{2} \mathrm{O}-0.5, \mathrm{CaCl}_{2}-0.5, \mathrm{KCl}-0.5, \mathrm{BaCl}_{2}-$ 0.2 [20];

- MSM 5: $\mathrm{NH}_{4} \mathrm{Cl}-4.0, \mathrm{NaNO}_{3}-2.0, \mathrm{~K}_{2} \mathrm{HPO}_{4}-1.8, \mathrm{MgSO}_{4} \cdot 7 \mathrm{H}_{2} \mathrm{O}-0.2, \mathrm{NaCl}-0.1$, $\mathrm{FeSO}_{4} \cdot 7 \mathrm{H}_{2} \mathrm{O}-0.01[21]$.

The composition of the selected media was formulated so that the suspended polymer, LDPE, was the sole carbon source for the microorganism. As a growth inducer, $0.1 \%$ glucose was added to the medium. The $\mathrm{pH}$ of the media was adjusted to 5.5, according to the physiological needs of the fungus.

Table 1. Nitrogen / phosphorus content and ratio in the tested mineral media

\begin{tabular}{c|c|c|l}
\hline $\begin{array}{c}\text { Mineral } \\
\text { media }\end{array}$ & $\begin{array}{c}\text { Nitrogen, } \\
\mathrm{g} / \mathrm{L}\end{array}$ & $\begin{array}{c}\text { Phosphorus, } \\
\mathrm{g} / \mathrm{L}\end{array}$ & Ratio N/P \\
\hline MSM 1 & 0.35 & 1.70 & $1 / 4.8$ \\
MSM 2 & 0.25 & 0.41 & $1 / 1.2$ \\
MSM 3 & 0.21 & 1.70 & $1 / 8$ \\
MSM 4 & 0.33 & 0.0 & $1 / 0$ \\
MSM 5 & 1.40 & 0.32 & $1 / 0.2$ \\
\hline
\end{tabular}

Each medium had 2 experimental variants - with LDPE films and without LDPE films (control variant). After 40 days of submerged cultivation, the following parameters were determined: catalase activity and $\mathrm{pH}$ of cultural media, quantity of accumulated biomass, the rate of LDPE degradation, optical microscopy of films. Also the tensile testing of polyethylene was performed using the tensile testing machine CQ-508B (COMETECH Testing Machines Co., LTD). Such parameters as elongation at break $(\%)$ and tensile strength at break $\left(\mathrm{N} / \mathrm{mm}^{2}\right)$ were determined.

The catalase test of cultural media was performed by the slide method. After 40 days of cultivation, the LDPE films were recovered, washed with sterile distilled water, air-dried and examined under an optical microscope.

The degradation of LDPE films was determined gravimetrically, by weighing the films before and after incubation. The fungal cell mass adhering to the polyethylene surface was washed by a $2 \%$ aqueous sodium dodecyl sulphate solution for 3 hours and finally with distilled water. The washed 
LDPE films were air-dried and weighed. Percentage degradation of polyethylene films was determined by the formula:

Weight loss $($ in \%) $=[($ Initial Weight - Final Weight $) /$ Initial Weight $] \times 100$.

\section{RESULTS AND DISCUSSION}

After submerged cultivation of $P$. verrucosum CNM-FP-02 strain for 40 days on different mineral media, with and without the addition of LDPE films, the activity of catalase and $\mathrm{pH}$ of the cultural media were determined (Table 2). It was observed that on MSM 1, 2, 3 and 5 the strain was catalase-positive, and on MSM media 4 catalase-negative. On the control media, the catalase activity had a weak reaction, while in the presence of LDPE the catalase activity was good (MSM 2, $3,5)$ and very good (MSM 1).

The $\mathrm{pH}$ index in the presence of LDPE became less acidic by 0.1 units in all media except MSM 5, where the $\mathrm{pH}$ became more acidic by 0.2 units.

Table 2. Catalase activity and $\mathrm{pH}$ of the cultural media after cultivation of $P$. verrucosum CNM FP-

02 on different MSM with and without plastic

\begin{tabular}{c|c|c|c|c}
\hline \multirow{2}{*}{$\begin{array}{c}\text { Mineral } \\
\text { media }\end{array}$} & \multicolumn{2}{|c}{ Catalase activity } & \multicolumn{2}{c}{$\mathrm{pH}$ of cultural media } \\
\cline { 2 - 5 } & $\begin{array}{c}\text { No } \\
\text { LDPE }\end{array}$ & $\begin{array}{c}\text { With } \\
\text { LDPE }\end{array}$ & $\begin{array}{c}\text { No } \\
\text { LDPE }\end{array}$ & $\begin{array}{c}\text { With } \\
\text { LDPE }\end{array}$ \\
\hline MSM 1 & + & ++++ & 5.3 & 5.4 \\
MSM 2 & + & +++ & 5.8 & 5.9 \\
MSM 3 & ++ & +++ & 5.5 & 5.6 \\
MSM 4 & - & - & 1.7 & 1.8 \\
MSM 5 & + & +++ & 6.1 & 5.9 \\
\hline
\end{tabular}

N.B.: + - Weak reaction, ++ - Moderate reaction, +++ - Good reaction, ++++ - Very good reaction (energetic).

It was observed that the presence of LDPE in the culture medium also influenced the growth activity of the strain, i.e. the amount of accumulated biomass (Fig. 1). Thus, on MSM 1, 2, 4, and 5, the stimulation of biomass growth by 19.1-93.33\% occurred. A significant increase was noted on MSM 2 (by 92.7\%) and MSM 3 (by 93.1\%). The addition of LDPE to MSM 3 had an opposed effect, decreased the fungal biomass accumulation by $29.3 \%$.

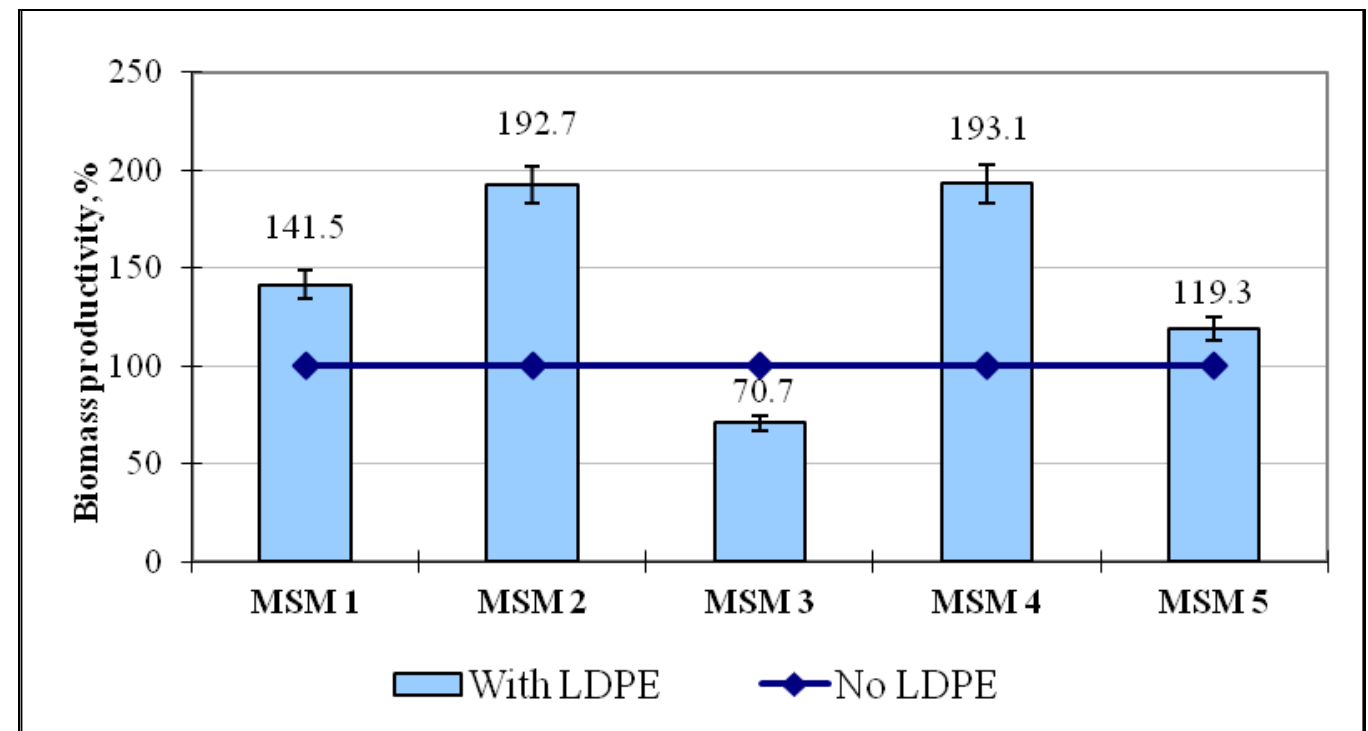

Fig. 1. Accumulation of $P$. verrucosum CNM FP-02 biomass on different mineral media, with and without LDPE

Weighing the LDPE strips after 40 days of cultivation showed that in the presence of the fungal strain the strips lost mass and the degradation processes of plastic had begun. The percentage of 
degradation was different, depending on the culture medium, from $0.41 \%$ to $0.92 \%$ (Fig. 2). The most active the LDPE films were degraded on medium MSM 2.

It has been observed that the amount of accumulated biomass does not always correlate with the degradation activity of LDPE (Fig. 2). Thus, on the medium MSM 4, the strain accumulated the highest amount of biomass, but the catalase test was negative and the plastic degradation was only $0.45 \%$. On the MSM 3 medium, although the strain accumulated less biomass than in the control, the catalase test was positive and the LDPE degradation was $0.49 \%$. On MSM 5 the strain accumulated more biomass than in the control, the catalase activity was good, but in the cultivation process the $\mathrm{pH}$ of the medium became more acidic, and the percentage of LDPE degradation was the lowest $-0.41 \%$. Thus, of all the tested media, MSM 2 proved to be the most favorable for catalase activity, biomass accumulation and LDPE degradation by strain the P. verrucosum CNMFP-02.

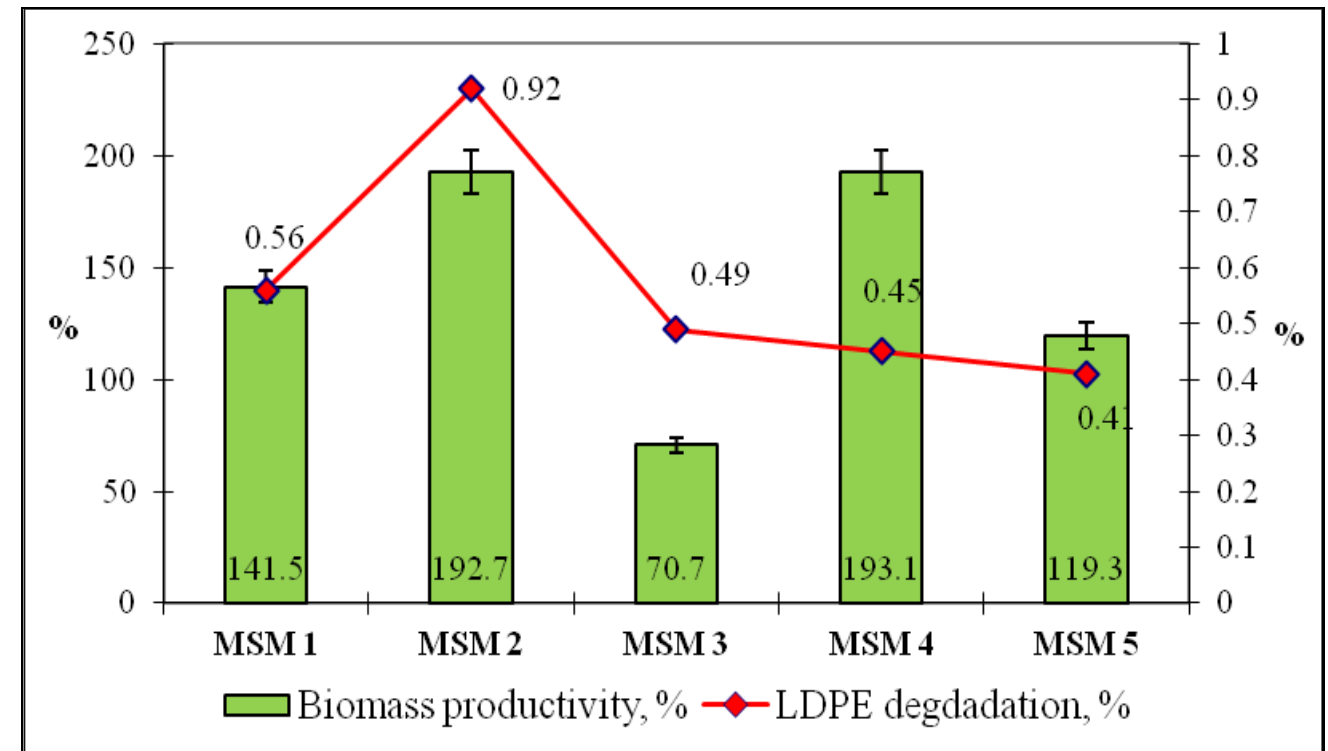

Fig. 2. LDPE degradation and the amount of $P$. verrucosum CNM FP-02 biomass on different MSM media

The study of LDPE films under an optical microscope revealed that after the contact with the fungal cells, both the immobilization of the microorganism and the damage on the polyethylene surface occurred (Fig. 3).
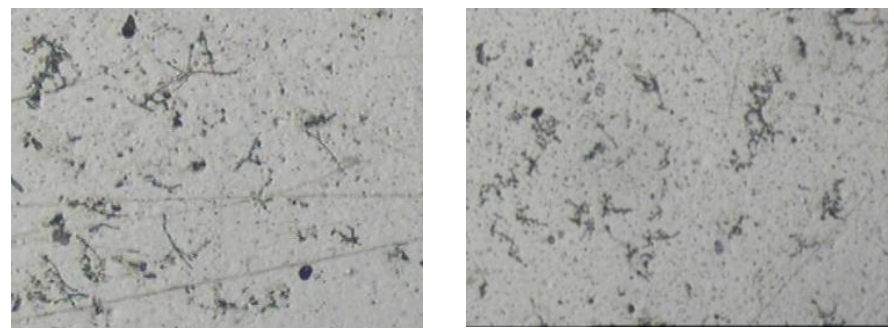

Immobilization of fungal hyphae on the surface of polyethylene

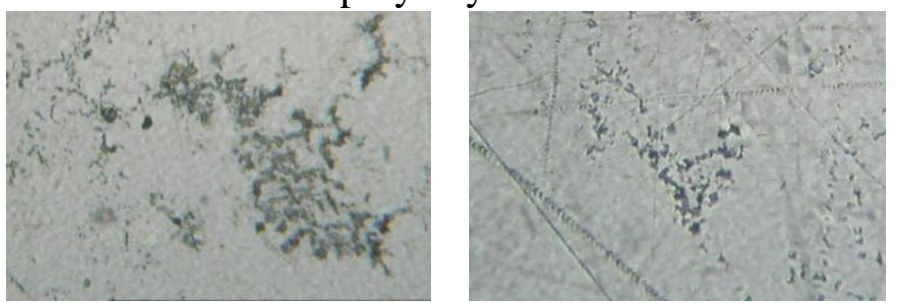

Traces of damage on the surface of polyethylene

Fig. 3. Photo of LDPE films after treatment with P. verrucosum CNM FP-02 strain 
Performing polyethylene tensile tests using the tensile testing machine CQ-508B showed that the elasticity of the films increased in the samples processed with microorganisms (Fig. 4). Thus, in the longitudinal strips, the elasticity most obviously changed on the MSM 2 medium (by $18.2 \%$ the tensile strength and by 39\% the elongation at break), followed by MSM 4 (with 12\% tensile strength and $27.6 \%$ elongation at break. The elasticity of the transverse bands increased the most on MSM 4 (by $9.7 \%$ the tensile strength and by $43.5 \%$ the elongation at break), followed by MSM 1 and MSM 5. The elasticity of LDPE, both longitudinal and transverse strips, practically did not changed on the MSM 3 medium, the tested values being within the limits of the control variant, or lower (the tensile strength $18 \%$ lower than in the control).

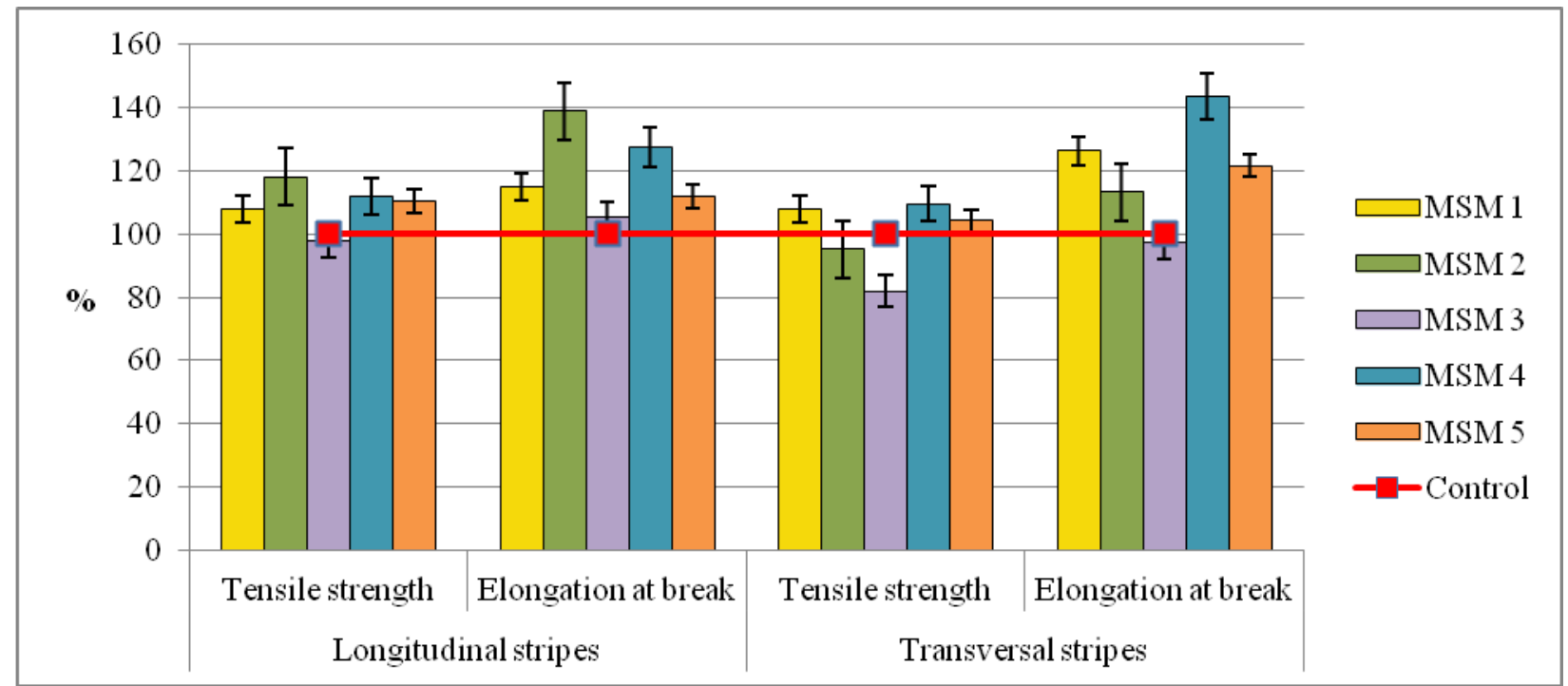

Fig. 4. The tensile strength and elongation at break of LDPE films treated with P. verrucosum CNM FP-02 strain, depending on the culture medium

Activation of the catalase ferment at the P. verrucosum CNM-FP-02 strain in the presence of plastic indicates the initiation of the enzymatic process of cleavage of the LDPE polymeric chains. Exoenzymes released by microorganisms acts at the initial stage of biodegradation by cleaving complex polymers into shorter chains of oligomers, dimers or monomers, which further pass the cell membrane and are used as a source of carbon and energy. The rate of microbial degradation is affected by both the environmental conditions as well as by polymer characteristics $[1,5,7,12,22]$. In our case, the environmental conditions such as $\mathrm{pH}$, composition and the ratio between nitrogen and phosphorus in the cultivation medium, had a decisive role on the growth and metabolic activity of the strain, respectively on the degradation of LDPE by P. verrucosum CNM-FP-02.

\section{CONCLUSIONS}

In conclusion we can say that the strain P. verrucosum CNM-FP-02 has the ability to modify the physical properties of LDPE film. Damaging the film surface and acting as a plasticizer, P.verrucosum CNM-FP-02 can lead to the biodegradation of LDPE film.

The most favorable conditions for the growth and activity of the fungus, as well as for the biodegradation of LDPE, were ensured by cultivation on MSM 2 medium, where the N/P ratio was $1: 1$.

\section{ACKNOWLEDGEMENTS}

This work has been realized with the support of State Program Project 20.80009.7007.03 „The microbiological potential in the degradation of non-recyclable plastic waste" (2020-2023). 


\section{REFERENCES}

[1] DEVI, R.S., KANNAN, V.R., NATARAJAN, K., NIVAS, D., KANNAN, K., CHANDRU, S. ANTONY, A.R., Environmental Waste Management, CRC Press., United States, 2016, p. 341-370.

[2] ISOBE, A., IWASAKI, S., UCHIDA, K., TOKAI, T., Nat. Commun., 10, no. 1, 2019, p. 417.

[3] GHATGE, S., YANG, Y., AHN, J.H., HUR, H.G., Appl. Biol. Chem., 63, 2020, p. 27.

[4] RAGAERT, K., DELVA, L., VAN GEEM, K., Waste Manage., 69, 2017, p. 24.

[5] GLASER, J. A., Plastics in the Environment, IntechOpen, London, 2019, p. 1-22, http://dx.doi.org/10.5772/intechopen.85124.

[6] CANOPOLI, L., COULON, F., WAGLAND, S. T., Sci. Total Environ., 698, 2020, p. 134125, https://doi.org/10.1016/j.scitotenv.2019.134125.

[7] IRAM, D., RIAZ, R.A., IQBAL, R.K., Open. J. Environ. Biol., 4, no. 1, 2019, p. 7, http://dx.doi.org/10.17352/ojeb.000010.

[8] JAMIL, S.U., ZADA, S., KHAN, I., SAJJAD, W., RAFIQ, M., SHAH, A.A., HASAN F., J. Cave Karst Stud., 79, no. 1, 2017, p. 73.

[9] ROSE, R.S., RICHARDSON, K.H., LATVANEN, E.J., et. al., Int. J. Mol. Sci., 21, no. 4, 2020, p. 1176.

[10] DIVYALAKSHMI, S., SUBHASHINI, A., IOSR- JESTFT, 10, no.12, 2016, p. 1.

[11] URBANEK, A.K., RYMOWICZ, W., MIROŃCZUK, A.M., Appl. Microbiol. Biotechnol., 102, 2018, p. 7669, https://doi.org/10.1007/s00253-018-9195-y.

[12] MOHANAN, N., MONTAZER, Z., SHARMA, P.K., LEVIN, D.B., Front. Microbiol., 11, 2020, p. 580709, https://doi.org/10.3389/fmicb.2020.580709.

[13] MONTAZER, Z., HABIBI-NAJAFI, M.B., MOHEBBI, M., OROMIEHEI, A., J. Polym. Environ., 26, 2018, p. 3613.

[14] MONTAZER, Z.H., NAJAFI, M.B., LEVIN, D.B., Polymers (Basel), 12, no. 1, 2020, p. 123, https://doi.org/10.3390/polym12010123.

[15] USHA, R., SANGEETHA, T., PALANISWAMY, M., Libyan Agric. Res. Cent. J. Intern., 2, 2011, p. 200.

[16] SKARIYACHAN, S., MEGHA, M., KINI, M.N., MUKUND, K.M., RIZVI, A., VASIST, K., Environ. Monit. Assess., 187, no. 1, 2015, p. 4174, https://doi.org/10.1007/s10661-014-4174-y.

[17] VIGNESH, R., CHARU DEEPIKA, R., MANIGANDAN, P., JANANI, R., IRJET, 3, no. 1, 2016, p. 2493.

[18] WILKES, R.A., ARISTILDE, L., J. Appl. Microbiol., 123, 2017, p. 582, https://doi.org/10.1111/jam.13472.

[19] NAKEI, M. D., Isolation and identification of plastics-degrading microorganisms from soils of Morogoro, Tanzania, A Dissertation for the degree of masters of science, The Sokoine University of Agriculture, Morogoro, Tanzania, 2015, http://www.suaire.sua.ac.tz/han dle/123456789/1013.

[20] GAJENDIRAN, A., KRISHNAMOORTHY, S., ABRAHAM, J., 3 Biotech., 6, no. 1, 2016, p. 52, https://doi.org/10.1007/s13205-016-0394-X.

[21] ZAJIC, E., SUPPLISON, B., Biotechnol. Bioeng., 14, 1972, p. 331.

[22] SIRACUSA, V., Polymers, 11, 2019, p. 1066, https://doi.org/10.3390/polym11061066.

Citation: Postolachi, O., Rastimesina, I., Josan, V., Mamaliga, V., Cotoman, A., Stati, D., Gutui, T., Screening of cultivation media for LDPE biodegradation by Penicillium verrucosum CNM-FP-02, Rom. J. Ecol. Environ. Chem., 2021, 3, no.2, pp. 48-53.

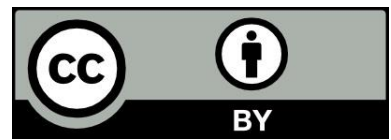

(C) 2021 by the authors. This article is an open access article distributed under the terms and conditions of the Creative Commons Attribution (CC BY) license (http://creativecommons.Org/licenses/by/4.0/). 